\title{
Alleviation of Pesticide Residue in Surface Water
}

\author{
Olubode Adeniyi ${ }^{1,2}$, Amy Hernandez ${ }^{1,2}$, Mark LeBlanc ${ }^{1,2}$, Joan M. King ${ }^{3}$, Marlene Janes ${ }^{3}$ \\ ${ }^{1}$ Agricultural Chemistry Department, Ag Center, Louisiana State University, Baton Rouge, Louisiana, USA \\ ${ }^{2}$ Pesticide Unit, Louisiana State Department of Agriculture and Forestry, Baton Rouge, Louisiana, USA \\ ${ }^{3}$ School of Nutrition and Food Science, Ag Center, Louisiana State University, Baton Rouge, Louisiana, USA \\ Email: oadeni1@lsu.edu
}

How to cite this paper: Adeniyi, O., Hernandez, A., LeBlanc, M., King, J.M. and Janes, M. (2017) Alleviation of Pesticide Residue in Surface Water. Journal of Water Resource and Protection, 9, 523-535. https://doi.org/10.4236/jwarp.2017.95034

Received: March 17, 2017

Accepted: April 27, 2017

Published: April 30, 2017

Copyright $\odot 2017$ by authors and Scientific Research Publishing Inc. This work is licensed under the Creative Commons Attribution International License (CC BY 4.0).

http://creativecommons.org/licenses/by/4.0/

\begin{abstract}
Reduction of environmental pollution incurred from pesticide use is very important. Zeolite is a natural mineral capable of removing certain chemical contaminants from water. This study was carried out to test the effect of zeolite treatment on pesticide residue alleviation in surface water. Ten surface water samples were treated with natural zeolite by filtering through. An EPA method was used to extract pesticide residue from the water samples and the surfactant used to modify the net charge on the zeolite was hexadecyltrimethylammonium chloride (HDTMA-Cl). Gas chromatography-mass spectrometry was used to analyze water samples. Alleviation was achieved in all the 10 water samples that were filtered through zeolite. The highest removal of pesticides from water with zeolite included $100 \%$ of bifenthrin in sample CLC, atrazine in BPH, CDG and LBT; metolachlor in CLC, LBT, BCH, TRH2 and $\mathrm{BPI}$; acetolachlor in $\mathrm{BBH}$ and $\mathrm{BCH}$; azoxystrobin in $\mathrm{BBH}$; desethylatrazine in $\mathrm{BCH}$ and $\mathrm{BPI}$; metribuzin in $\mathrm{BCH}, \mathrm{TRH} 2$ and $\mathrm{BPI}$; and both clomazone and bromacil in sample BDC. A minimum reduction of $10.9 \%$ was found for metolachlor in sample BRH. Further reduction of pesticide residues up to $50 \%$ was recorded in the SMZ treatment as the concentrations of 4 out of 8 pesticide residues were reduced. This study confirms the potential of both the natural zeolite-Clinoptilolite, and SMZ of alleviating pesticide residues in water.
\end{abstract}

\section{Keywords}

EPA (United States Environmental Protection Agency),

Gas Chromatography, Mass Spectrometry, Zeolite,

Hexadecyltrimethylammonium Chloride (HDTMA-Cl),

Surface-Modified-Zeolite (SMZ), Bifenthrin, Metolachlor, Metribuzin,

Acetolachlor, Azoxystrobin, Desethylatrazine, Clomazone, Bromacil,

Atrazine, Clinoptilolite, Alleviation 


\section{Introduction}

A clean environment is required for maintaining good health and agricultural sustainability. Regular use of pesticides in modern day agriculture demands the need to devise a means of removing or reducing possible pesticide residues from our environment. Waters that are available in the environment where pesticides are used are of high risk of harboring pesticide residues. Leaching enhances environmental pollution as chemicals drain from the treated region to non-targeted environments. Therefore, surface waters have the potential of getting contaminated when irrigation water that has passed over pesticide-treated environment leaches into the surface waters [1]. Storms could sometime result in spontaneous flow of contaminated water into surface water [2]. Another source of pollution is drift that occurs if a pesticide spray misses its targets having been deflected by wind or resulting from human error, thereby, landing on a nontargeted area. When the level of the pesticide contamination reaches a critical level in food, ground waters, lakes, rivers or ponds, it becomes an issue that could lead to illness or death in the organisms that depend on them.

Due to its unique attributes, zeolite is a mineral with the potential of removing chemical contaminants from water as earlier published [3] [4]. Some of the past efforts made in removing pesticide residues in water include the use of clay [3] [5], activated carbon [6] [7] and ozonization [6]. Use of clay is limited by its adsorption capacity due to its shrink-swell behavior and zeolites are free of such flaws [8]. Saturation of carbon filters resulting in cost of replacement; and a decrease in the efficiency of activated carbon with increased organic contaminants are limitations in the use of activated carbon [9]. Formation of byproducts like peroxides, ozonides, organobromine and bromate is associated with the use of ozonization [9]. A natural zeolite like clipnotilolite is high in cation exchange capacity due to its net negative charge on the outer surface [10] [11] [12]. When a natural zeolite is fortified with an overall positive charge using a surfactant, its affinity for cation changes for anion and it entraps negatively charged organic ions such as chromate and hydrophobic organic ions [13] [14]. Clinoptilolite has high affinity for chromate and selenium and organic hydrophobics [15] and also for $\mathrm{Pb}^{2+}[16]$ when modified by hexadecyltrimethylammonium bromide

(HDTMA-Br). These unique attributes of a zeolite are both utilized in this study as we seek to alleviate pesticide residues in surface waters across Louisiana. This article reports the evaluation of natural zeolite, and HDTMA-Cl surface-modified-zeolite on pesticide residue alleviation in surface water.

\section{Materials and Methods}

\subsection{Water Sample Storage and Preparation}

Ten surface water samples were collected from different locations in Louisiana. These were sourced from the pool of samples from the Pesticide Laboratory of the Agricultural Chemistry department, Louisiana State University through the Louisiana State Department of Agriculture and Forestry (LDAF). Water samples and their sources were as listed in Table 1. Each sample was labeled after its 
Table 1. Water samples

\begin{tabular}{cc}
\hline Water & Source \\
\hline BPH & Bayou Pierre, Hwy 1 S of Powha $\left({ }^{*}\right.$ WM-S-A-01) \\
CLC & Chatlin Lake Canal, Hwy 457 T2N (WM-S-A-04) \\
CDG & Coulee Des Grues, hwy 115-SW (WM-S-A-05) \\
BCH & Big Creek Hwy 80 at Holly Ridge (WM-S-M-03) \\
LBT & Lake Bruin T12N R12E S29 (WM-S-M-06) \\
TRH2 & Tensas River Hwy 15 at Clayon (WM-S-M-07) \\
BPI & Bayou Portage I-10 at Henderson (WM-S-O-07) \\
BDC & Bayou De Cannes, Hwy 98 2 MI, W (WM-S-C-03) \\
BBH & Black Bayou, Hwy 530 2 MI. E. of Foley AL 36535 (WM-S-S-01) \\
BRH & Boeuf River, Hwy 2 T2 IN R8E S25 Eunice LA (WM-S-M-01) \\
\hline
\end{tabular}

${ }^{*} \mathrm{WM}=$ Water monitoring.

source by abbreviating the name of the source. For instance, sample BPH was obtained from Bayou Pierre, Hwy $1 \mathrm{~S}$ of Powha. All water samples were stored at $4^{\circ} \mathrm{C}$ until each was analyzed.

\subsection{Pesticide Residue Extraction in Fresh Surface Water}

The method used for pesticide residue extraction in surface water is same as earlier described [17]. Analyte samples, positive and negative controls were prepared in 2 replicates in vials and analyzed.

\subsection{Water Filtration through Natural Zeolite-Clinoptilolite}

Ten water samples-BPH, CLC, CDG, BBH, BRH, BCH, LBT, TRH, BPI, and $B D C$, were selected from the original pool of 35 samples of surface water studied for detection of pesticide residues. The criterion used in selecting those $10 \mathrm{sam}$ ples was the water samples that had the most pesticide residues based on the results from a similar study [17]. As shown in Figure 1, each of the 3 compartments of the water filtration system used to filter surface water samples from top to bottom contained $20 \mathrm{~g}$ each, of gravel, sand and Zeolite. A funnel was placed on the topmost column and filtration was initiated. The filtrate was collected into a 1 liter amber color bottle as shown in Figure 1(b). For each water sample, a total of $1000 \mathrm{ml}$ was filtered per $20 \mathrm{~g}$ of zeolite after which the filtration system was dismantled, cleaned by hot wash in soap, rinsed in running potable water three times and allowed to dry before re-assembled and re-used. Fresh zeolite was used for each sample.

\subsection{Preparation of HDTMA-Cl (Hexadecyltrimethylammonium Chloride)-Surface-Modified Zeolite}

As earlier described [18], 0.056 M surfactant (HDTMA-Cl) was prepared to treat the natural zeolite. On a weighing balance, $1.43 \mathrm{~g}$ HDTMA-Cl was measured and poured into a $125 \mathrm{ml}$ beaker containing $70 \mathrm{ml}$ of milliQ water. With a gentle 


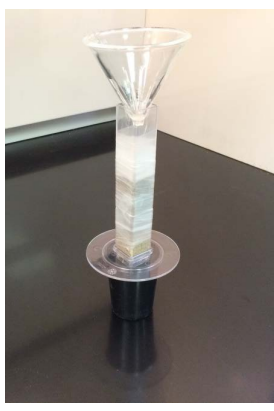

(a)

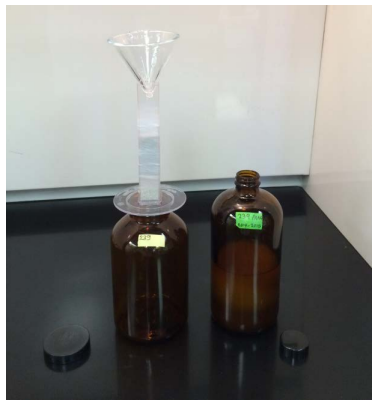

(b)

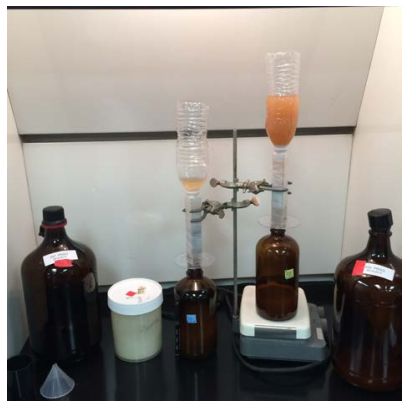

(c)

Figure 1. (a) Water filtration system. ((b) \& (c)) Surface water filtration through zeolite and HDTMA-Cl SMZ.

swirl until all surfactant dissolved, solution was poured into $100 \mathrm{ml}$ graduated cylinder and milliQ water added up to $80.5 \mathrm{ml}$ final volume. Twenty gram of natural zeolite was dispersed in the $80.5 \mathrm{ml}$ of $0.056 \mathrm{M}$ surfactant for 2 hours. The supernatant was drained away after 2 hours and the surface-modified zeolite (SMZ) was spread out on a clean aluminum foil to air dry overnight.

\subsection{Water Filtration through HDTMA-Cl-Surface-Modified Zeolite}

The water sample BRH was selected based on its highest volume of pesticide residue content. The filtration system for SMZ consisted of 3 columns in layers. The upper layer was empty followed by a middle layer of natural zeolite and base layer of HDTMA-Cl-SMZ.

\subsection{Pesticide Residue Extractions in Both Zeolite-Filtered, and SMZ-Filtered Waters}

As listed in Table 2, ten zeolite-filtered water samples were extracted for pesticide residues. The same extraction method used in pesticide residue extraction in fresh surface water as earlier stated was repeated for both sets of samples-10 zeolite-filtered samples and $1 \mathrm{SMZ}$-filtered sample. In each case, the same volume of $1000 \mathrm{ml}$ of water was ran through the natural zeolite and the SMZ accordingly. Sample vials for the GC-MS were prepared and analyzed.

\subsection{Gas Chromatography-Mass Spectrometry}

GC-MS analysis was the same as earlier described [17]. On column concentration of the samples were calculated. Spiking rate was computed and the efficiency of the methodology was confirmed through the value of the spike recovery. On column concentration expected from a spike was calculated and it provided a clue to where matrix standard needed to be in order to use it to calculate the recovery rate. The amount of sample represented in the liquid injected onto column was calculated. Parameters obtained regarding the quantitation and retention time are as outlined in Table 3.

\subsection{Statistical Analysis}

Statistical analytical system (SAS) was employed to run paired student T-test in 
Table 2. Effect of zeolite treatment on pesticide residue (ppb) in surface water.

\begin{tabular}{|c|c|c|c|c|c|c|c|}
\hline Sample & $\mathrm{pH}$ & Origin & Reduction & Pesti Resid & Before & After & $\%$ Reduction \\
\hline \multirow[t]{2}{*}{ BPH } & 7.7 & 2 & 2 & Atrazine & 0.2 & ND & 100 \\
\hline & & & & Metolachlor & 0.16 & 0.12 & 25 \\
\hline \multirow[t]{4}{*}{ CLC } & 7.7 & 4 & 4 & Atrazine & 6.48 & 0.06 & 99.1 \\
\hline & & & & Desethatz & 0.74 & 0.55 & 25.7 \\
\hline & & & & Metolachlor & 1.08 & ND & 100 \\
\hline & & & & Bifenthrin & 0.02 & 0 & 100 \\
\hline \multirow[t]{2}{*}{ CDG } & 7.2 & 2 & 2 & Atrazine & 0.68 & ND & 100 \\
\hline & & & & Metolachlor & 0.84 & 0.73 & 13.1 \\
\hline \multirow[t]{4}{*}{$\mathrm{BBH}$} & 7.2 & 4 & 4 & Atrazine & 1.78 & 1.26 & 29.2 \\
\hline & & & & Metolachlor & 1.16 & 1.01 & 12.9 \\
\hline & & & & Acetolachlor & 0.06 & $\mathrm{ND}$ & 100 \\
\hline & & & & Azoxystrobin & 0.02 & ND & 100 \\
\hline \multirow[t]{8}{*}{$\mathrm{BRH}$} & 7.3 & 8 & 8 & Atrazine & 6.2 & 0.64 & 89.7 \\
\hline & & & & Clomazone & 2.4 & 1.54 & 35.8 \\
\hline & & & & Desethatz & 0.62 & 0.38 & 38.7 \\
\hline & & & & Metribuzin & 0.34 & 0.17 & 50 \\
\hline & & & & Metolachlor & 17.2 & 15.32 & 10.9 \\
\hline & & & & Propanil & 0.08 & 0.03 & 62.5 \\
\hline & & & & Metalaxyl & 0.08 & 0.06 & 25 \\
\hline & & & & Dimethenamid & 0.16 & 0.12 & 25 \\
\hline \multirow[t]{5}{*}{ LBT } & 7.7 & 5 & 3 & Desethatz & 0.22 & 0.17 & 22.7 \\
\hline & & & & Atrazine & 0.6 & ND & 100 \\
\hline & & & & Metolachlor & 0.36 & ND & 100 \\
\hline & & & & Glyphosate & ND & ND & ND \\
\hline & & & & AMPA & ND & ND & ND \\
\hline \multirow[t]{6}{*}{$\mathrm{BCH}$} & 7.1 & 6 & 5 & Atrazine & 6.24 & 1.4 & 77.6 \\
\hline & & & & Desethatz & 0.54 & ND & 100 \\
\hline & & & & Acetolachlor & 0.28 & ND & 100 \\
\hline & & & & Metribuzin & 0.36 & ND & 100 \\
\hline & & & & Metolachlor & 3.9 & ND & 100 \\
\hline & & & & Clomazone & 0.04 & ND & ND \\
\hline \multirow[t]{6}{*}{ TRH2 } & 7.2 & 6 & 5 & Atrazine & 0.38 & 0.16 & 57.9 \\
\hline & & & & Desethatz & 0.26 & 0.06 & 76.9 \\
\hline & & & & Metribuzin & 0.3 & ND & 100 \\
\hline & & & & Metolachlor & 3.4 & ND & 100 \\
\hline & & & & Clomazone & 0.18 & ND & ND \\
\hline & & & & Azoxystrobin & 0.06 & 0.02 & 66.7 \\
\hline \multirow[t]{4}{*}{ BPI } & 7.2 & 7 & 6 & Atrazine & 0.72 & 0.22 & 69.4 \\
\hline & & & & Desthatz & 0.2 & ND & 100 \\
\hline & & & & Metribuzin & 0.28 & ND & 100 \\
\hline & & & & Metolachlor & 0.74 & ND & 100 \\
\hline
\end{tabular}




\section{Continued}

\begin{tabular}{|c|c|c|c|c|c|c|c|}
\hline & & & & Metalaxyl & 0.12 & 0.1 & 16.7 \\
\hline & & & & Clomazone & 0.04 & ND & $\mathrm{ND}$ \\
\hline & & & & Azoxystrobin & 0.06 & 0.04 & 33.3 \\
\hline \multirow[t]{5}{*}{$\mathrm{BDC}$} & 6.8 & 5 & 2 & Clomazone & 0.3 & ND & 100 \\
\hline & & & & Bromacil & 0.42 & ND & 100 \\
\hline & & & & Metalaxyl & 0.04 & ND & $\mathrm{ND}$ \\
\hline & & & & Metolachlor & 0.06 & ND & $\mathrm{ND}$ \\
\hline & & & & Propiconazole & 0.12 & ND & $\mathrm{ND}$ \\
\hline
\end{tabular}

Origin $=$ original pesticide residue in surface water; Reduction $=$ reduced amount of pesticide residue in surface water; Pesti resid = pesticide residue; Desethat $=$ Desethylatrazine; before $=$ pesticide residue $(\mathrm{ppb})$ in water sample before filtration through zeolite; $1^{\text {st }}$ and $2^{\text {nd }}=$ First and second pesticide residue quantitation reading after filtration through zeolite; $\mathrm{PR}=$ pesticide residue; $\mathrm{ND}=$ non-detected.

Table 3. Retention time and quantitation ion for target compounds and their degradation products.

\begin{tabular}{|c|c|c|c|c|c|}
\hline Compund & $\mathrm{t}_{\mathrm{R}}(\min )$ & $\mathrm{Q}_{\text {ion }}(\mathrm{m} / \mathrm{z})$ & Compound & $t_{\mathrm{R}}(\min )$ & $\mathrm{Q}_{\mathrm{ion}}(\mathrm{m} / \mathrm{z})$ \\
\hline Acetochlor & 6.87 & 223 & Hexazinone & 9.01 & 171 \\
\hline Alachlor & 6.95 & 188 & Malathion & 7.2 & 173 \\
\hline Atrazine & 6.5 & 200 & MB45950fm & 7.29 & 420 \\
\hline Azoxystrobin & 11.51 & 344 & MB46136fm & 7.8 & 383 \\
\hline Bifenthrin & 8.57 & 181 & MB46513,Fip. met. & 6.76 & 388 \\
\hline Bromacil & 7.5 & 207 & Metalaxyl & 7.1 & 249 \\
\hline Captan & 7.8 & 79 & Methyl Parathion & 7.16 & 263 \\
\hline Captan deg. & 5.67 & 79 & Metolachlor & 7.22 & 162 \\
\hline Carbofuran & 6.65 & 164 & Metribuzin & 7.18 & 198 \\
\hline Carbofuran deg. & 4.08 & 164 & Molinate (Ordram) & 5.57 & 126 \\
\hline Chlorpyrifos & 7.26 & 197 & Norflurazon & 8.76 & 303 \\
\hline Clomazone & 6.53 & 125 & Pendameth & 7.5 & 252 \\
\hline Cyanazine & 7.57 & 225 & Prometone & 6.34 & 225 \\
\hline Cyfluthrin 1 & 9.69 & 206 & Propicon 1 & 8.56 & 259 \\
\hline Cyfluthrin 3 & 9.76 & 206 & Propicon2 & 8.59 & 259 \\
\hline Cypermet1 & 9.88 & 181 & Prometryn & 7.05 & 241 \\
\hline Cypermet2 & 9.95 & 181 & Propanil & 7.1 & 161 \\
\hline Desethylatrazine & 6.24 & 172 & Tebupirimiphos & 6.42 & 261 \\
\hline DesIsopropylatz & 6.28 & 173 & Tefluthrin & 6.17 & 177 \\
\hline Diazinon & 6.4 & 137 & Terbacil & 6.93 & 161 \\
\hline Dimethenamid & 6.91 & 154 & Terbufos & 6.4 & 231 \\
\hline Eptam & 4.24 & 128 & Thimet & 6.17 & 75 \\
\hline Esfenvalera1 & 10.36 & 167 & Trifluralin & 5.6 & 306 \\
\hline Esfenvalerate & 10.45 & 167 & $\lambda$-cyhalot1 & 8.91 & 181 \\
\hline Etridiazole & 5.04 & 183 & $\lambda$-cyhalot & 8.99 & 197 \\
\hline Fipronil & 7.35 & 367 & & & \\
\hline
\end{tabular}

$\lambda=$ lambda; DesIsopropylAtz = desisopropylatrazine; MB46136fm = MB46136, Fip. met.; MB45950 = MB45950, Fip. met. Pendameth $=$ Pendamethalin; Propicon2 = Propiconazole 2; Propicon $1=$ Propiconazole $1 ; \lambda$-cyhalot $1=$ Lambda-cyhalothrin $1 ; \lambda$-cyhalot $=$ Lambda-cyhalothrin; Cypermethrin $1=$ Cypermet 1 Cypermethrin 2 = Cypermet2; Esfenvalerate $1=$ Esfenvalera1. 
order to compare the concentration of pesticide residues in the water samples before and after zeolite treatments. The alpha value was set at $\mathrm{P}=0.05$. That is, when the calculated P-value is less than 0.05 then a statistical difference can be declared.

\section{Results}

\subsection{Role of Natural Zeolite in Pesticide Alleviation}

Reduction in pesticide residues was observed in the 10 zeolite-filtered surface waters analyzed (Table 2).

As shown in Table 2, reduction in pesticide residue levels following zeolite filtration ranged from the minimum of $10.9 \%$ to a maximum of $100 \%$. Minimum reduction was recorded in metolachlor in sample $\mathrm{BRH}$, while the maximum were in atrazine in samples BPH, CDG and LBT; metolachlor in samples CLC, LBT, BCH, TRH2 and BPI; bifenthrin in sample CLC; acetolachlor in BBH and $\mathrm{BCH}$; azoxystrobin in $\mathrm{BBH}$; desethylatrazine in $\mathrm{BCH}$ and $\mathrm{BPI}$; metribuzin in $\mathrm{BCH}, \mathrm{TRH} 2$ and BPI; and both clomazone and bromacil in sample BDC. A high reduction rate of $99.1 \%$ was found in atrazine in the same sample CLC. Atrazine was also alleviated in sample BRH up to $89.7 \%$. Moderately high rates of reductions were also found in atrazine at the rate of $77.6 \%$ in sample $\mathrm{BCH} ; 57.9 \%$ in sample TRH2; and $69.4 \%$ in sample BPI. Reductions recorded in sample BRH included 50\% metribuzin and $62.5 \%$ propanil; and in sample TRH2 was $66.7 \%$ azoxystrobin.

Statistics of the means comparison for the pesticide residues found before and after filtering water through natural zeolite using a paired student t-test is as shown in Table 4 at $\mathrm{P}_{\text {critical }}=0.05$. The difference between the atrazine levels before and after filtration of water sample through natural zeolite was highly significant in CLC and was significant in BRH and BCH. Difference between the atrazine levels was not significant in samples $\mathrm{BBH}$ and TRH2. Second analysis of BPI atrazine was not detected and therefore paired t-test not applicable. No statistical difference was found between the desethylatrazine levels before and after zeolite treatment in samples CLC and BRH and LBT. No significant difference was found before and after treatment with zeolite for the pesticide levels in metolachlor in samples $\mathrm{BPH}, \mathrm{CDG}$ and $\mathrm{BBH}$. There was no statistical difference between desethylatrazine levels before and after zeolite treatment in CLC, BRH and LBT.

\subsection{Role of Surfactant-Modified-Zeolite (SMZ) in Pesticide Alleviation}

As summarized in Table 5, following SMZ treatment of sample BRH, 6 pesticides were detected out of 8 . Propanil and dimethenamid were undetected after SMZ treatment.

Greater reduction of pesticide residues was recorded (Table 6) in the sample $\mathrm{BRH}$ that was filtered through the surfactant-modified-zeolite (SMZ). A 50\% reduction was observed as 4 out of the 8 residues found were reduced following 
Table 4. Paired t-test comparison of pesticide residue means before and after zeolite treatment.

\begin{tabular}{ccccccc}
\hline Sample & PR & Before & After & Means \pm SD & Pr $>|t|$ & Sig. \\
\hline BPH & Metolachlor & 0.16 & 0.12 & $0.04 \pm 0.03$ & 0.3 & NS \\
CLC & Atrazine & 6.48 & 0.06 & $6.42 \pm 0.00$ & 0.0001 & $\star \star *$ \\
& Desethatz & 0.74 & 0.55 & $0.10 \pm 0.14$ & 0.5 & NS \\
CDG & Metolachlor & 0.84 & 0.73 & $0.11 \pm 0.01$ & 0.06 & NS \\
BBH & Atrazine & 1.78 & 1.26 & $0.52 \pm 0.11$ & 0.1 & NS \\
& Metolachlor & 1.16 & 1.01 & $0.15 \pm 0.0 .13$ & 0.34 & NS \\
BRH & Atrazine & 6.2 & 0.64 & $5.56 \pm 0.31$ & 0.03 & $\star$ \\
& Desethatz & 0.62 & 0.38 & $0.10 \pm 0.50$ & 0.83 & NS \\
LBT & Desethatz & 0.22 & 0.17 & $0.13 \pm 0.01$ & 0.05 & NS \\
BCH & Atrazine & 6.24 & 1.4 & $4.84 \pm 1.84$ & 0.01 & $\star \star$ \\
TRH2 & Atrazine & 0.38 & 0.16 & $0.29 \pm 0.04$ & 0.07 & NS \\
BPI & Atrazine & 0.72 & ND & NA & NA & NA \\
BDC & Metolachlor & 0.06 & ND & NA & NA & NA \\
\hline
\end{tabular}

Sig. = Significance; NS $=$ no significant difference found among the pesticide residue levels recorded before and after treatment with natural zeolite clinoptilolite; ${ }^{*}{ }^{* * *}=$ significant difference and highly significant difference respectively found among the pesticide residue levels recorded before and after treatment with natural zeolite clinoptilolite; $\mathrm{SD}$ = standard deviation; $\mathrm{SE}$ = standard error; $\mathrm{PR}=$ pesticide residue; $\mathrm{df}$ (degree of freedom $)=1 ; \operatorname{Pr}>|t|=$ calculated $\mathrm{P}$ value by SAS; Alpha $=0.05$ (critical P value); NA = not applicable.

Table 5. Effect of surfactant-modified-zeolite (SMZ) on pesticide residue in surface water.

\begin{tabular}{|c|c|c|c|c|c|}
\hline \multirow{3}{*}{ Sample } & \multicolumn{5}{|c|}{ Pesticide Residue (ppb) } \\
\hline & & \multirow{2}{*}{ Before } & \multicolumn{2}{|c|}{ After } & \multirow{2}{*}{ Mean \pm SD } \\
\hline & & & $1 \mathrm{st}$ & 2nd & \\
\hline \multirow[t]{8}{*}{$\mathrm{BRH}$} & Atrazine & 6.2 & 0.34 & 0.28 & $0.31 \pm 0.04$ \\
\hline & Clomazone & 2.4 & 1.12 & 0.84 & $0.98 \pm 0.20$ \\
\hline & Desethylatrazine & 0.62 & 0.5 & 0.34 & $0.42 \pm 0.01$ \\
\hline & Metribuzin & 0.34 & 0.24 & 0.22 & $0.23 \pm 0.01$ \\
\hline & Metolachlor & 17.2 & 10.16 & 7.82 & $8.99 \pm 1.66$ \\
\hline & Metalaxyl & 0.08 & 0.04 & 0.04 & $0.04 \pm 0.00$ \\
\hline & Propanil & 0.08 & $\mathrm{ND}$ & $\mathrm{ND}$ & NA \\
\hline & Dimethenamid & 0.16 & $\mathrm{ND}$ & ND & NA \\
\hline
\end{tabular}

$\mathrm{SD}=$ standard deviation; $\mathrm{ND}=$ not detected.

Table 6. Percentage reduction of the pesticide residue $(\mathrm{ppb})$ in surface water filtered through SMZ.

\begin{tabular}{ccccccc}
\hline Sample & PR & BZ & AZ & ASMZ & \% Zeolite reduction & \% SMZ reduction \\
\hline BRH & Atrazine & 6.2 & 0.64 & 0.31 & 89.7 & 95 \\
& Clomazone & 2.4 & 1.54 & 0.98 & 35.8 & 59.2 \\
& Desethylatrazine & 0.62 & 0.38 & 0.42 & 38.7 & 32.3 \\
& Metribuzin & 0.34 & 0.17 & 0.23 & 50 & 32.4 \\
& Metolachlor & 17.2 & 15.32 & 8.99 & 10.9 & 47.7 \\
& Metalaxyl & 0.08 & 0.06 & 0.04 & 25 & 50 \\
\hline
\end{tabular}

$\mathrm{BZ}=$ before zeolite treatment; AZ = after zeolite treatment; ASMZ = after surface-modified-zeolite; SMZ = surface-modified-zeolite; $\mathrm{PR}=$ pesticide residue. 
filtration through SMZ. The 4 compounds that were reduced by SMZ compared to filtration through natural zeolite included atrazine @ 95\% compared to $89.7 \%$ reduction with natural zeolite (NZ); 59.2\% clomazone compared with $35.8 \%$ with NZ; $47.7 \%$ metolachlor compared with $10.9 \%$ with NZ and 50\% metalaxyl compared with $25 \%$ with NZ.

As outlined in Table 7, paired t-test means comparison of pesticide residue before and after SMZ treatment was conducted. A significant difference $\left(\mathrm{P}_{\text {calc }}=\right.$ 0.003 ) was found in atrazine between the pesticide level recorded before and after the SMZ treatment of sample BRH. A highly significant difference $\left(\mathrm{P}_{\text {calc }}<\right.$ 0.0001) was similarly found in metalaxyl levels before and after SMZ treatment. In pesticide levels recorded for clomazone, desethylatrazine, metribuzin and metolachlor, there was no statistical difference found among them.

Further paired t-test comparison of pesticide levels was conducted between the levels recorded after treatment with natural zeolite and the levels recorded after treatment with surfactant-modified-zeolite. The outcome of this as outlined in Table 8 showed a statistical difference in metalaxyl, and the difference ob-

Table 7. Paired t-test comparison of pesticide residue means before and after SMZ treatment.

\begin{tabular}{ccccc}
\hline Sample & PR & Mean $\pm S D$ & $\operatorname{Pr}>|t|$ & Sig. \\
\hline BRH & Atrazine & $5.89 \pm 0.04$ & 0.003 & $* * *$ \\
& Clomazone & $1.42 \pm 0.20$ & 0.06 & NS \\
& Desethatz & $0.20 \pm 0.11$ & 0.24 & NS \\
& Metribuzin & $0.11 \pm 0.01$ & 0.06 & NS \\
& Metolachlor & $8.21 \pm 1.66$ & 0.09 & NS \\
& Metalaxyl & $0.04 \pm 0.00$ & $<0.0001$ & $* * *$ \\
\hline
\end{tabular}

${ }^{*}$ Sig. = Significance; NS = no significant difference found among the pesticide residue levels recorded before and after treatment with Hexa decyl trimethyl chloride surfactant-modified-zeolite clinoptilolite; ${ }^{*}=$ very significant difference found between the pesticide residue levels recorded before and after treatment with HDTM-Cl SMZ; SD = standard deviation; $\mathrm{SE}=$ standard error; $\mathrm{PR}=$ pesticide residue; $\mathrm{df}$ (degree of freedom $)=1 ; \operatorname{Pr}>|t|=$ calculated $\mathrm{p}$ value by SAS; Alpha $=0.05$ (critical $\mathrm{p}$ value)

Table 8. Paired t-test comparison of levels of PR (ppb) of zeolite-treated and SMZ-treated sample.

\begin{tabular}{ccccc}
\hline Sample & PR & Mean \pm SD & $\operatorname{Pr}>|t|$ & Sig \\
\hline BRH & Atrazine & $0.33 \pm 0.04$ & 0.06 & NS \\
& Clomazone & $0.56 \pm 0.20$ & 0.16 & NS \\
& Desethatz & neg0.04 \pm 0.11 & 0.71 & NS \\
& Metribuzin & neg0.06 \pm 0.01 & 0.11 & NS \\
& Metolachlor & $6.33 \pm 1.66$ & 0.12 & NS \\
& Metalaxyl & $0.02 \pm 0.00$ & $<0.0001$ & $* * *$
\end{tabular}

Sig. = Significance; NS = no significant difference found among the pesticide residue levels recorded between zeolite treated and SMZ treated sample BRH; ${ }^{* *}=$ highly suignificant difference found among the pesticide residue levels recorded between zeolite treated and SMZ treated sample BRH; SD = standard deviation; $\mathrm{SE}=$ standard error; $\mathrm{PR}=$ pesticide residue; $\mathrm{df}=$ degree of freedom; $\mathrm{Pr}>|\mathrm{t}|=$ calculated $\mathrm{p}$ value by SAS; Alpha $=0.05$ (critical p value). 
served was highly significant $\left(\mathrm{P}_{\text {calc }}<0.0001\right)$. No statistical difference between treatment was observed for atrazine, clomazone, desethylatrazine, metribuzin and metolachlor. However, negative mean value and $t$ value computed for desethylatrazine and metribuzin showed a negative trend because the levels recorded after filtration through the SMZ was higher than the levels after filtration through the natural zeolite. As outlined in Table 6, after filtration through natural zeolite desethylatrazine level was reduced from original $0.62 \mathrm{ppb}$ to $0.38 \mathrm{ppb}$ compared to $0.42 \mathrm{ppb}$ for SMZ. After filtration through zeolite, metribuzin level was reduced from 0.34 to 0.17 compared to $0.23 \mathrm{ppb}$ recorded after filtration through SMZ.

\section{Discussions}

As obtained in this study, adsorption of metalaxyl using zeolite has been earlier reported [4]. Reduction in atrazine recorded in this study is similar to two reports earlier published [3], [19], even though they used SDBAC (stearyldimethylbenzylammoniumchloride) as surfactant to modify the zeolite and HDTMA - $\mathrm{Cl}$ (hexadecyltrimethylammonium chloride) was used in this study as modifying surfactant. Further reduction of atrazine, clomazone, metolachlor and metalaxyl after filtration through SMZ conforms to the theoretical principle of effect of exchanging CEC (cation exchange capacity) property of clinoptilolite with an anion exchange capacity, thereby enhancing its ability to retain negatively charged organic ions that ordinarily would have escaped. Differences recorded in the $\mathrm{pH}$ (ranging from 6.8 through 7.7) of the surface water samples may have impacted the cation exchange capacity of the zeolite. This finding is in agreement with the result of a similar study [20] where they confirmed that the success of clinoptilolite in removing organic contaminations is a function of $\mathrm{pH}$, temperature, contact duration, and initial concentrations of humic acid and ammonia. Pesticide residues were alleviated in all the samples whose $\mathrm{pH}$ ranged between 7.1 through 7.7, while the low pH 6.8 in sample BDC might be responsible for those pesticide residues that were non-detected. Similar to the assertion [20] that the optimum temperature at which zeolite could reduce organic contaminants in water is about room temperature which was the reason while sample waters were always allowed to acclimatize to room temperature after retrieved from cold storage. Findings in this study may also imply that water samples need to be above neutral $\mathrm{pH}$ in order for the zeolite to work at its optimum as earlier suggested [21] that sample water needs to be about the $\mathrm{pH}$ of natural water ( $\mathrm{pH}$ 7.0) for the detection of residues to be at its best. High atrazine level of $6.2 \mathrm{ppb}$ originally detected in the BRH sample which was reduced to $0.64 \mathrm{ppb}$ when treated with zeolite, and further reduced to $0.31 \mathrm{ppb}$ when treated with SMZ confirmed the adsorption capacities of the natural zeolite (clinoptilolite) and HDTMA-Cl SMZ as a potential remedy to the concentrations of this herbicide in surface water. Some residues were not detected in the water samples and this could be due to their low concentration probably tending toward infinitesimal amount as GC-MS detection limits were surpassed. It could also mean that they have been totally removed from the sample by the SMZ treatment. As op- 
posed to the expected event that enhanced reduction be observed when filtered through SMZ, a reversed trend observed in desethylatrazine and metribuzin may imply that they have greater affinity for natural zeolite than for zeolite modified by HDTMA-Cl surfactant. Great affinities of clinoptilolite zeolite for ammonium ion [22] and that of SMZ for chromate and selenite [15] are an indication that any trace amount of $\mathrm{NH}_{4}{ }^{+}$, chromate or selenate in any of the 10 samples studied in this section may have been reduced. However, lack of measurement of these ions limited us from any information regarding this aspect. Part of future work would be to examine water for metal contaminants like arsenic [23] [24]; Fe and $\mathrm{Mn}$ [25]; $\mathrm{Cd}$ and $\mathrm{Pb}[26] ; \mathrm{Pb}^{2+}[16]$, and the cation $\mathrm{NH}_{4}{ }^{+}$.

\section{Conclusion}

Results obtained in the reduction of atrazine, metolachlor, bifenthrin, clomazone, desethylatrzine, metribuzin, propanil and metalaxyl are good to build upon as modern scientists aspire to provide a permanent solution to pesticide residues in surface water. This could be a basis for a large scale pesticide reduction in other forms of water like ground water and potable water as time goes on. Development of an industrial scale filtration system that could utilize zeolite as water filtration medium will be required in order to put the results obtained in this study into the effective use that will impact communities, national and international boundaries. Simplicity of this method with its low cost filtration system, coupled with the fact that it is free of any form of health risk will enhance its practical use and eventually lead to a global adoption of this methodology.

\section{Acknowledgements}

We appreciate the Louisiana State Department of Agriculture and Forestry for the support of this study.

\section{References}

[1] Starner, K., Spurlock, F., Gill, S., Goh, K., Feng, H., Hsu, J., Lee, P., Tran, D. and White, J. (2005) Pesticide Residue in Surface Water from Irrigation-Season Monitoring in the San Joaquin Valley, California, USA. Bulletin of Environmental Contamination and Toxicology, 74, 920-927. https://doi.org/10.1007/s00128-005-0669-0

[2] Laurie, B., Sauvage, S., Srinivasan, R., Leccia, O. and Sanchez-Perez, J.-M. (2014) Application Date as a Controlling Factor of Pesticide Transfers to Surface Water during Runoff Events. CATENA, 119, 97-103. https://doi.org/10.1016/j.catena.2014.03.013

[3] Lemic, J., Kovacevic, D., Tomasevic-Canovic, M., Kovacevic, D., Stanic, T. and Pfend, R. (2006) Removal of Atrazine, Lindane and Diazinone from Water by Organo-Zeolites. Water Research, 40, 1079-1085. http://www.sciencedirect.com/science/article/pii/S0043135406000078 https://doi.org/10.1016/j.watres.2006.01.001

[4] De Smedt, C., Ferrer, F., Leus, K. and Spanoghe, P. (2015) Removal of Pesticides from Aqueous Solutions by Adsorption on Zeolites as Solid Adsorbents. Adsorption Science \& Technology, 33, 457-485. https://doi.org/10.1260/0263-6174.33.5.457

[5] Li, H., Sheng, G., Teppen, B.J., Johnston, C.T. and Boyd, S.A. (2003) Sorption and 
Desorption of Pesticides by Clay Minerals and Humic Acid-Clay Complexes. Soil Science Society of America Journal, 67, 122-131. https://doi.org/10.2136/sssaj2003.0122

[6] Boussahel, R., Bouland, S., Moussaoui, K.M. and Montiel, A. (2000) Removal of Pesticide Residues in Water Using the Nanofiltration Process. Desalination, 132, 205-209. https://doi.org/10.1016/S0011-9164(00)00151-X

[7] Ogata, F., Tominaga, H., Yabutani, H. and Kawasaki, N. (2011) Removal of Estrogens from Water Using Activated Carbon and Ozone. Journal of Oleo Science, 60, 609-611. https://doi.org/10.5650/jos.60.609

[8] Tarasevich, Y.I. and Polyakov, V.E. (1995) Demanganation of Artesian Waters Using Modified Clinoptilolite. Natural Zeolites, Sofia'95, 65-67.

[9] Welte, B., Montiel, A. and Dupas, S. (1996) Evolution de la concentration en pesticides dans deux filteres de traiterment d'eau de surface. Source Resources, 3, 28-32.

[10] Colella, C. (1996) Ion Exchange Equilibria in Zeolita Minerals. Mineralium Deposita, 31, 554-562. https://doi.org/10.1007/BF00196136

[11] Pansini, M. (1996) Natural Zeolites as Cation Exchangers for Environmental Protection. Mineralium Deposita, 31, 563-575. https://doi.org/10.1007/BF00196137

[12] Ibrahim, K.M. and Akashah, T. (2004) Lead Removal from Wastewater Using Faujasite Tuff. Environmental Geology, 46, 865-870. https://doi.org/10.1007/s00254-004-1074-4

[13] Li, Z., Roy, S.J., Zou, Y. and Bowman, R.S. (1998) Long-Term Chemical and Biological Stability of Surfactant-Modified Zeolite. Environmental Science and Technol$o g y, 32,628-2632$.

[14] Krishna, B.S., Murty, D.S.R. and Jai Prakash, B.S. (2001) Surfactant-Modified Clay as Adsorbent for Chromate. Applied Clay Science, 20, 65-71. https://doi.org/10.1016/S0169-1317(01)00039-4

[15] Campos, V., Morais, L.C. and Buchler, P.M. (2007) Removal of Chromate from Aqueous Solution Using Treated Natural Zeolite. Environmental Geology, 52, 1521 1525. https://doi.org/10.1007/s00254-006-0596-3

[16] Bowman, R.S., Haggerty, G.M., Huddleston, R.G., Neel, D. and Flynn, M.M. (1995) Surfactant-Enhanced Subsurface Remediation. ACS Symposium Series 594, American Chemical Society, Washington, DC, 54-64. In: Campos, V., Morais, L.C. and Buchler, P.M., Eds., Removal of Chromate from Aqueous Solution Using Treated Natural Zeolite, Environmental Geology, 52, 1521-1525.

[17] Adeniyi, O., Hernandez, A., LeBlanc, M., King, J. and Janes, M. (2016) Quantitation of Pesticide Residue in Water and Food in Louisiana, USA. Journal of Water Resource and Protection, 8, 1145-1157. https://doi.org/10.4236/jwarp.2016.812089

[18] Bowman, R. (2005) Surfactant-Altered Zeolites as Permeable Barriers for the in-Situ Treatment of Contaminated Groundwater. New Mexico Tech Technical Report 0522, $46 \mathrm{p}$.

[19] Lemić, J., Tomašević-Čanović, M., Adamović, M., Kovačević, D. and Milićević, S. (2007) Competitive Adsorption of Polycyclic Aromatic Hydrocarbons on OrganoZeolites. Microporous and Mesoporous Materials, 105, 317-323. https://doi.org/10.1016/j.micromeso.2007.04.014

[20] Karmen, M., Logar, N.Z., Sijeg, M. and Farkas, A. (2013) Chapter 5 Natural Zeolites in Water Treatment-How Effective Is Their Use. In: Elshorbagy, W. and Kabir Chowdhury, R., Eds., Water Treatment, INTECH. https://doi.org/10.5772/50738

[21] Moussavia, G., Talebi, S., Farrokhi, M. and Sabouti, R.M. (2011) The Investigation of Mechanism, Kinetic and Isotherm of Ammonia and Humic Acid Co-Adsorption 
onto Natural Zeolite. Chemical Engineering Journal, 171, 1159-1169.

[22] Mumpton, F.A. (1999) La roca magica: Uses of Natural Zeolites in Agriculture and Industry. Proceedings of the National Academy of Sciences of the United States of America, 96, 3463-3470. https://doi.org/10.1073/pnas.96.7.3463 http://www.ncbi.nlm.nih.gov/pmc/articles/PMC34179/?tool=pubmed

[23] Sullivan, E.J., Carey, J.W. and Bowman, R.S. (1998) Thermodynamics of Cationic Surfactant Sorption onto Natural Clinoptilolite. Journal of Colloid and Interface Science, 206, 369-380. https://doi.org/10.1006/jcis.1998.5764

[24] Bowman, R.S. (2003) Applications of Surfactant-Modified Zeolites to Environmental Remediation. Microporous and Mesoporous Materials, 61, 43-56. https://doi.org/10.1016/S1387-1811(03)00354-8

[25] Inglezakis, V.J., Doula, M.K., Aggelatou, V. and Zorpas, A.A. (2010) Removal of Iron and Manganese from Underground Water by Use of Natural Minerals in Batch Mode Treatment. Desalination and Water Treatment, 18, 341-346. https://doi.org/10.5004/dwt.2010.1102

[26] Ćurković, L., Cerjan-Stefanović, Š. and Filipan, T. (1997) Metal Ion Exchange by Natural and Modified Zeolites. Water Research, 31, 1379-1382.

https://doi.org/10.1016/S0043-1354(96)00411-3

\section{Scientific Research Publishing}

Submit or recommend next manuscript to SCIRP and we will provide best service for you:

Accepting pre-submission inquiries through Email, Facebook, LinkedIn, Twitter, etc. A wide selection of journals (inclusive of 9 subjects, more than 200 journals)

Providing 24-hour high-quality service

User-friendly online submission system

Fair and swift peer-review system

Efficient typesetting and proofreading procedure

Display of the result of downloads and visits, as well as the number of cited articles

Maximum dissemination of your research work

Submit your manuscript at: http://papersubmission.scirp.org/

Or contact jwarp@scirp.org 